\title{
The Research on the Simulation about Heat Loss in a 220t/h Circulating Fluidized Bed Boiler
}

\author{
Huan Liu ${ }^{1,2, a}$, Guoli Qi ${ }^{2, b}$,Songsong Zhang ${ }^{2, c}$,Zhongwei Wang ${ }^{2}$, Jian Guan $^{2}$ \\ ${ }^{1}$ Xuefu road no. 52 in nangang district of Harbin in heilongjiang province P.R.China \\ ${ }^{2}$ Building 2,Hepingjie,Xiyuan,Chaoyang District,Beijng,P.R.China \\ a279706648@qq.com, bwenyuhe0616@126.com, czhangsong0536@163.com
}

\begin{abstract}
Keywords: circulating fluidized bed boiler, numerical simulation, heat loss
Abstract. A 220t/h circulating fluidized bed boiler is selected as a research object, the heat loss of the circulating fluidized bed boiler is studied by numerical simulation while the three major parts including the furnace body of the circulating fluidized bed boiler ,cyclone separator and rear smoke channel are seen as a core of the research. The surface temperature of the boiler is got by simulating the process of heat transfer about thermal insulation materials of boiler entity. The three major parts of heat loss about the circulating fluidized bed boiler is calculated by calculative formulas of heat loss and relevant parts of the surface area which is got from the specification about the design of boilers. The three parts of the surface temperature which is get from simulating respectively are: the surface temperature of the parts of furnace is $48.5^{\circ} \mathrm{C}$, the surface temperature of the parts of the cylinder about cyclone separator is $94.46^{\circ} \mathrm{C}$, the surface temperature of the parts of the vertebra is $97.88^{\circ} \mathrm{C}$, the surface temperature of the rear smoke channel is $48.90{ }^{\circ} \mathrm{C}$.Each part of the heat loss respectively are: $128.706 \mathrm{KW}, 76.359 \mathrm{KW}, 57.069 \mathrm{KW}$.
\end{abstract}

\section{Introduction}

At present, China's energy situation can be described as: the per capita energy consumption in China is low, the use efficiency of energy is not high, the per capita energy is short, the environmental constraints are emerging. Therefore, protecting and saving coal energy are the major topics in China or even in the world[1].As a country in which coal is the main energy, boiler is China's major power equipment which makes the coal as the main fuel. Circulating fluidized bed boiler has many advantages including wide adaptability of fuel, high efficiency in combustion, low $\mathrm{NO}_{\mathrm{X}}$ emission and so on. Now the number of circulating fluidized bed boiler in China is increasing constantly.So it has practical significance and is also necessary in researching the heat loss of circulating fluidized bed boiler[2].Although the principle of heat transfer is given by heat loss calculation formula in domestic standards for ASME and EPRI, but it's rarely used in reality. At the same time, the parameter is still got from the cooling curve of pulverized coal boiler in domestic, there is few research methods which are combined with theoretical numerical simulation and heat transfer[3]. Due to the difference in structure between circulating fluidized bed boiler and pulverized coal furnace, there must be big difference in heat loss between that two. There will be great influences on the performance and operation of circulating fluidized bed boiler if the boiler efficiency cannot be got accurately by getting heat loss failing.

Therefore, the theoretical heat loss of this operating boiler can be concluded by simulating heat transfer study on the three major parts including the furnace body of the circulating fluidized bed boiler ,cyclone separator and rear smoke channel in a running power plant and calculating heat loss in this three parts through combining the relevant heat transfer principle after getting the surface temperature by using finite element method in this article.

\section{The design parameters of each part of circulating fluidized bed boiler}

The parameters about the furnace of circulating fluidized bed boiler as shown in table 1 . The design parameters about cyclone separator of circulating fluidized bed boiler as shown in table 2. The parts of 
the design parameters about the vertebral body of cyclone separator shown in table 3 . The design parameters about rear smoke channel shown in table 4.

Table1. Part of the design parameters about the furnace of circulating fluidized bed boiler

\begin{tabular}{|c|c|c|c|}
\hline Material & $\begin{array}{c}\text { Thickness } \\
(\mathrm{mm})\end{array}$ & $\begin{array}{c}\text { Density } \\
\left(\mathrm{kg} / \mathrm{m}^{3}\right)\end{array}$ & $\begin{array}{c}\text { Thermal conductivity } \\
(\mathrm{W} / \mathrm{m} \cdot \mathrm{K})\end{array}$ \\
\hline $\begin{array}{c}\text { Production of silicate } \\
\text { aluminum }\end{array}$ & 76.2 & 96 & 0.13 \\
\hline $\begin{array}{c}\text { Rock wool insulation } \\
\text { blanket }\end{array}$ & 150 & 150 & 0.05104 \\
\hline Steel plate & 2 & 7850 & 48 \\
\hline
\end{tabular}

Table2 Parts of the design parameters about the main part of cyclone separator

\begin{tabular}{|c|c|c|c|}
\hline Material & Thickness $(\mathrm{mm})$ & $\begin{array}{c}\text { Density } \\
\left(\mathrm{kg} / \mathrm{m}^{3}\right)\end{array}$ & $\begin{array}{c}\text { Thermal conductivity } \\
(\mathrm{W} / \mathrm{m} \cdot \mathrm{K})\end{array}$ \\
\hline High-alumina brick & 65 & 3470 & 5.0 \\
\hline $\begin{array}{c}\text { Cement swelling } \\
\text { vermiculite stone blocks }\end{array}$ & 50 & 350 & 0.0812 \\
\hline Rock wool & 90 & 150 & 0.06148 \\
\hline Steel plate & 4 & 7850 & 48 \\
\hline
\end{tabular}

Table3 Parts of the design parameters about the vertebral body of cyclone separator

\begin{tabular}{|c|c|c|c|}
\hline Material & thickness $(\mathrm{mm})$ & $\begin{array}{c}\text { Density } \\
\left(\mathrm{kg} / \mathrm{m}^{3}\right)\end{array}$ & $\begin{array}{c}\text { Thermal conductivity } \\
(\mathrm{W} / \mathrm{m} \cdot \mathrm{K})\end{array}$ \\
\hline $\begin{array}{c}\text { Silicate aluminum } \\
\text { refractory fiber felt }\end{array}$ & 80 & 240 & 0.113 \\
\hline Cement perlite products & 120 & 350 & 0.09323 \\
\hline Steel plate & 4 & 7850 & 48 \\
\hline
\end{tabular}

Table 4 The design parameters about rear smoke channel

\begin{tabular}{|c|c|c|c|}
\hline Material & $\begin{array}{c}\text { Thickness } \\
(\mathrm{mm})\end{array}$ & $\begin{array}{c}\text { Density } \\
\left(\mathrm{kg} / \mathrm{m}^{3}\right)\end{array}$ & $\begin{array}{c}\text { Thermal conductivity } \\
(\mathrm{W} / \mathrm{m} \cdot \mathrm{K})\end{array}$ \\
\hline High-alumina bricks & 120 & 3470 & 5.0 \\
\hline Air layers & 20 & 29 & 0.023 \\
\hline Common red bricks & 235 & 1700 & 0.638 \\
\hline
\end{tabular}

\section{The selection of each part of heat transfer coefficient about circulating fluidized bed boiler}

2.1 The selection of heat transfer coefficient about the furnace of circulating fluidized bed boiler Since the heat transfer characteristics that particles swash in the furnace of circulating fluidized bed boiler and the dynamic characteristics about high temperature airflow are so complex, which makes the distribution nonuniform on a variety of physical properties in the furnace inside and the change in bed's height and bed's diameter direction. But the heat transfer coefficient in the furnace inside is in a range for circulating fluidized bed boiler. By looking for information, some range of heat transfer coefficient about CFB boiler are shown in table 5. 
Table5 Some range of heat transfer coefficient about CFB boiler

\begin{tabular}{|c|c|c|c|}
\hline $\begin{array}{c}\text { The location of factories } \\
\text { Evaporation }\end{array}$ & Evaporation $\left(\mathrm{M} \cdot \mathrm{W}_{\mathrm{th}}\right)$ & $\begin{array}{c}\text { The size of furnace } \\
(\text { length } \times \text { width } \times \text { height })(\mathrm{m})\end{array}$ & $\begin{array}{c}\text { Heat transfer } \\
\text { coefficient }\left(\mathrm{W} / \mathrm{m}^{2} \mathrm{~K}\right)\end{array}$ \\
\hline $\begin{array}{c}\text { Chalmers university of Sweden } \\
\text { (Andersson and Leckner) }\end{array}$ & 12 & $1.7 \times 1.7 \times 13.5$ & $100 \sim 160$ \\
\hline Chatham, Canada(Coutuier etc. $)$ & 72 & $3.96 \times 3.96$ & $170 \sim 220$ \\
\hline $\begin{array}{c}\text { Flensfberg, Germany } \\
\text { (Werdermann and Werther) }\end{array}$ & 109 & $5.13 \times 5.13$ & $177 \sim 157$ \\
\hline $\begin{array}{c}\text { Point Aconi, Canada (Leming } \\
\text { Chen) }\end{array}$ & 165 & $7 \times 18 \times 36$ & $120 \sim 170$ \\
\hline
\end{tabular}

The internal surface is covered by a layer of film in the furnace of circulating fluidized bed boiler, heat will be passed to the heating surface going by gas film in two ways including radiation and conduction when the gas film is contacted with particle groups: heat will be transferred to heating surface in the form of convection when the gas film is contacted with gas phase medium; at the same time particle groups are also in the way of radiation heat transfer because of its separation by gas.

Therefore, the heat transfer coefficient $h$ between the internal surface of the CFB furnace wall and particulate media can be broken down into three components: the convective heat transfer coefficient of gas $h_{g c}$, the convective heat transfer coefficient of particle groups $h_{c c}$, and the radiation heat transfer coefficient of particle groups $h_{r}$, it is that:

$$
h=h_{c c} \delta_{c}+h_{g c}\left(1-\delta_{c}\right)+h_{r}
$$

In the formula above, the main part of heat transfer coefficient of medium $h$ is the the convective heat transfer coefficient of particle groups $h_{c c}$.

The form of heat transfer in the furnace of circulating fluidized bed boiler and pulverized coal boiler is different, particles produce strong radiation and convection to the water wall because of its large heat capacity.Therefore, the overall heat transfer coefficient of the bed to heating surface can reach $200 \mathrm{~W} /\left(\mathrm{m}^{2} \cdot \mathrm{K}\right)$ in the combustion chamber of circulating fluidized bed boiler which is greater than average fixed bed boiler and pulverized coal boiler. Therefore the inside of the heat transfer coefficient of the furnace wall cooling is temporarily set as $200 \mathrm{w} /\left(\mathrm{m}^{2} \cdot \mathrm{K}\right)$ because of its area $(9.364 \mathrm{~m} \times 6.636 \mathrm{~m} \times$ $38.419 \mathrm{~m}$ ) for this $220 \mathrm{t} / \mathrm{h}$ circulating fluidized bed boiler with tube light furnace.

\subsection{The determination of heat transfer coefficient about cyclone separator}

The high temperature material which is separated from the combustion chamber rotate at a high speed in cyclone separator, the flue gas carrying a lot of material will scour surface, therefore the heat transfer coefficient of the inside of cyclone separator will be so large, the temperature value of the inside wall of cyclone separator will be given directly in simulation which is regarded as the first boundary condition to deal with.

Because of the large amount of material in cyclone separator and the enough fast flush speed of the flue gas, the difference of the temperature distribution in the medial wall of cyclone separator is not too large. Due to the national standard GB/T 753-2012, "For the matching of machine and furnace capacity in the unit system of the unit, the rated capacity of boiler should not be less than the amount of admission of the steam turbine which is running in the rated power,the maximum continuous evaporation of boiler should match the amount of admission when the steam turbine is in the most high power", so the selected temperature in this simulation should be almost $10 \%$ lower than the rated temperature.It is got from the specification of the boiler design that the rated temperature of boiler is $950^{\circ} \mathrm{C}$, so the inner wall temperature of cyclone separator in this simulation is $850^{\circ} \mathrm{C}$.

The outboard of the cyclone separator belongs to the third kind boundary condition, there are two cooling ways including a large space of natural convection and radiation cooling about the wall heat transfer of cyclone separator, due to the arrangement of more than one boiler in the boiler room, the 
radiation in thermal equilibrium is formed between the outer wall of boiler,so the large space of natural convection is only considered in this calculation. The boiler room temperature is got as $25^{\circ} \mathrm{C}$ from the simulation of furnace.

\subsection{The selection of heat transfer coefficient of rear smoke channel}

The inlet and outlet temperature of flue gas about three parts of the superheater of rear smoke channel, economizer and air preheater are summarized in the table 6 below.

Table 6The part of flue gas temperature of rear smoke channel

\begin{tabular}{|c|c|c|}
\hline Structure & $\begin{array}{c}\text { The inlet temperature of flue } \\
\text { gas }\left({ }^{\circ} \mathrm{C}\right)\end{array}$ & $\begin{array}{c}\text { the outlet temperature of flue } \\
\text { gas }\left({ }^{\circ} \mathrm{C}\right)\end{array}$ \\
\hline Low temperature superheater & 671 & 471 \\
\hline Economizer & 471 & 261 \\
\hline Air preheater & 261 & 126 \\
\hline
\end{tabular}

The outer rear smoke channel belongs to the third boundary condition, the heat transfer in the outer wall of the rear smoke channel includes two heat dissipation methods, because there are more than one boiler which are arranged in the boiler room,the radiation heat transfer balance is formed within the outer walls of the boiler,therefore the large space natural convention is only concerned in calculation.

The radiation heat transfer coefficient of the rear smoke channel which is in economizer is 11.734 $\mathrm{W} /\left(\mathrm{m} 2 \cdot{ }^{\circ} \mathrm{C}\right)$, it is considered that the economizer and the wall of rear smoke channel share the same radiation layer thickness and the flow gas medium temperature, thus the radiation heat transfer coefficient. of the rear smoke channel is considered as $11.734 \mathrm{~W} /\left(\mathrm{m} 2 \cdot{ }^{\circ} \mathrm{C}\right)$. Because the status of the flow gas runoff is Laminarflow in the economizer, therefore the overall transfer coefficient of the rear smoke channel is $11.734 \mathrm{~W} /\left(\mathrm{m} 2 \cdot{ }^{\circ} \mathrm{C}\right)$ ignoring the convective heat transfer coefficient.

When the flue gas entered the tail duct, the temperature of flue gas was lower than the $600 \sim 700^{\circ} \mathrm{C}$. Not melting ash in the flue gas and condensation of vapor of alkali metal oxides were over. What's more, the ash entering tail duct had different grain sizes, belong to the wide-screening composition. They are generally less than $200 \mu \mathrm{m}$ mostly being $10 \sim 20 \mu \mathrm{m}$. Therefore, the flue gas flow in the rear smoke channel is typical smoke and strong turbulence of mixture of fly ash particles in gas-solid two-phase flow [4]. So there is the need to lay the refractory wear tiles inside the tail duct and should retain the air layer in the Middle, stacking insulation bricks at the outside tail duct.

\section{Each part of the physical model and calculation model of circulating fluidized bed boiler}

\subsection{Parts of the physical model and heat loss calculation model in circulating fluidized bed boiler furnace}

According to local boilers and boiler design specification (Figure 1) can be obtained the circulating fluidized bed using furnace wall cladding tube light.Circulating fluidized bed, the temperature distribution of the water-cooled tube with a fin affected by tube outer heat transfer coefficient, the tube unit heat transfer coefficient, and thermal conductivity of water pipe metal,to determine the specific heat transfer coefficient value in water wall inside has the certain difficulty. Due to the quantity of heat conduction in water cooling tube longitudinal direction is very small, so the heat flux on the pipe cross section can be approximately regarded as a two-dimensional distribution. On the basis of the theory, the furnace wall is simplified as the cell structure of two-dimensional model to simulate, qualitative cell structure shown in Figure 2. 


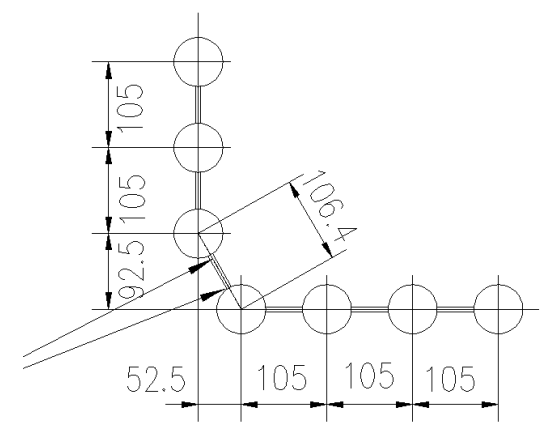

Figure 1 Boiler local figure

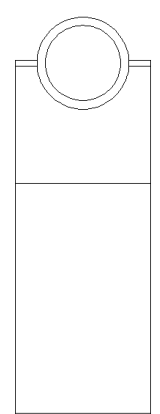

Figure2 Furnace wall qualitative unit structure

Existing laboratory data indicate that the factor having the greatest influence on the combustion bed combustion chamber of the heating surface heat transfer coefficient is a material particle concentration, and the greater the concentration of particulate material, the heat transfer coefficient also increases[5]. Therefore, the furnace is considered as a uniform distribution of various physical properties to calculate the overall total of the furnace heat loss is unreasonable. So it is necessary to calculate segmentation, the chamber is divided into several sections that various physical properties in each segment is considered distributed uniformly, the parameters for each section are considered consistent, then calculate heat loss for each zone, and summed to obtain the total heat loss of the entire furnace section.

Heat transfer coefficient with increasing height of the furnace showing a decreasing trend, it is because with increasing height measuring point, the furnace flue gas temperature can be increased and then decreased, and reaches a minimum at the furnace exit, in the middle of the highest furnace value.Heat transfer coefficient with increase of furnace is showing a decrease trend,This is due to the increase of the height of measuring point, the furnace flue gas temperature can be increased and then decreased, and reaches a minimum at the furnace exit, reaches the highest value in the middle of furnace.In addition, with the increase of the height of measuring point, the reduce extent of the fly ash concentration is bigger, so that the heat transfer coefficient also decreases with the furnace height.At the same time the furnace heat transfer coefficient will increase significantly with the increase of the load. This is due to the increase of the load can not only improve the level of temperature in the furnace, meanwhile the concentration of fly ash particles in the furnace is increased[6].

According to the material particles concentration along the furnace height direction is divided into dense phase zone and dilute phase zone, For the research of this paper, The calculation of heat loss is also divided into dense phase zone and dilute phase zone to calculate.

The so-called multi-layer wall, which is composed of several layers of different materials stacked together to form a composite wall.For example, using fire-resistant layer, insulating brick layers and common brick laminated together to make the boiler furnace wall, is a kind of multilayer wall.For ease of discussion, the following with a three-layer wall shown in Fig. 3 as a subject for discussion. The connection between layers is assumed good, without introducing additional thermal resistance,temperature landing will happen through the interface between the layers.so the temperature through the inter-layer interface would not be dropped.Known to the thickness of each layer is $\delta_{1}$, $\delta_{2} 、 \delta_{3}$, The coefficient of thermal conductivity of each layer is $\lambda_{1}, \lambda_{2}, \lambda_{3}$,And the temperature of the outer surface of the two-layer wall is $t_{1} t_{4}$, To determine the heat flux through the wall of the multi-layer and the temperature layer between layers of flat wall. 


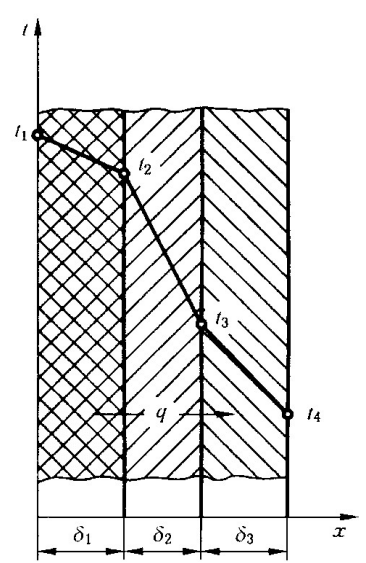

Figure 3 layers of flat wall thermal conductivity

Each layer of thermal resistance expression as follows:

$$
\begin{aligned}
& \frac{t_{1}-t_{2}}{q}=\frac{\delta_{1}}{\lambda_{1}} \\
& \frac{t_{2}-t_{3}}{q}=\frac{\delta_{2}}{\lambda_{2}} \\
& \frac{t_{3}-t_{4}}{q}=\frac{\delta_{3}}{\lambda_{3}}
\end{aligned}
$$

Application in series process of total thermal resistance is equal to the sum of the points and thermal resistance:

$$
\frac{t_{1}-t_{4}}{q}=\frac{\delta_{1}}{\lambda_{1}}+\frac{\delta_{2}}{\lambda_{2}}+\frac{\delta_{3}}{\lambda_{3}}
$$

So the formula of heat flux as follow:

$$
q=\frac{t_{1}-t_{4}}{\frac{\delta_{1}}{\lambda_{1}}+\frac{\delta_{2}}{\lambda_{2}}+\frac{\delta_{3}}{\lambda_{3}}}
$$

And so on,the calculation formula of the $\mathrm{N}$ layer is

$$
q=\frac{t_{1}-t_{n+1}}{\sum_{i=1}^{n} \frac{\delta_{i}}{\lambda_{i}}}
$$

The heat dissipation is that final heat flux multiply the total surface area of the outer surface .

\subsection{The physical model and calculation model about cyclone separator in circulating fluidized} bed boiler

It is got from the specification of the boiler design that the structure of the cyclone separator is adiabatic type, at the same time getting from the reference drawing the cyclone separator is tube type and it is consisted of the cylinder and cone.the cyclone separator with the size of the three-dimensional model is set up as shown in figure 4 . 


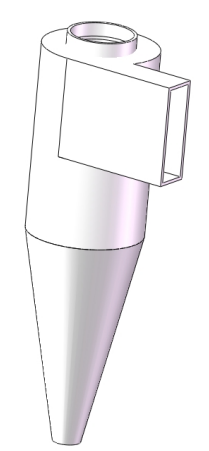

Figure 4 cyclone separatthree-dimensional model

After burned in the combustion chamber, a large amount of bed material particles are carried into the cyclone separator by the flue gas,and revolve at a high speed inside the cyclone separator. Solid bed material particles under the action of centrifugal force are isolated from flue gas and along the bottom of the cone flow flow back to feed tube[7].

The cylinder section and the cone section of the cyclone separator are masonried by different materials, and the cylinder section can be simplified as a two-dimensional model, however, the cone section needs to be simulated with the stereoscopic $3 \mathrm{D}$ model,therefore the cylinder section and the

cone section are separated for simulating and calculating the heat loss, the overall heat loss is calculated at the end.

The masonry structure of the cyclone separator has experienced several generations of change,the first generation of cyclone separator uses pouring layers which is fixed with the pin ,the refractory layer of the high aluminum refractory brick which is used in the second generation of cyclone separator is more wear-resisting than the first generation's ,the barrel refractory layer of the third generation cyclone separator is consisted with the three layers including the high aluminum refractory brick, heat insulation refractory brick and thermal insulation layer.

The characteristics of the structure about high temperature cyclone are simple, metal shell is lined with refractory inside and thermal insulation material outside. The scheme of cyclone separator in the design conforms is to the characteristics of adiabatic cyclone separator, so it was simulated as the requirements of the adiabatic cyclone separator.

The calculation model is a cylindrical wall, which is considered to be $r_{1} 、 r_{2}$ respectively. The internal and external surface temperatures are maintained at a constant temperature ${ }^{t_{1}} 、 t_{2}$, As shown in Figure 3, In cylindrical coordinate $\operatorname{system}(r, \varphi, z)$, this problem becomes one dimensional heat conduction along the radius direction.For ease of analysis, the thermal conductivity of the material $(\lambda)$ is equal to the constant.

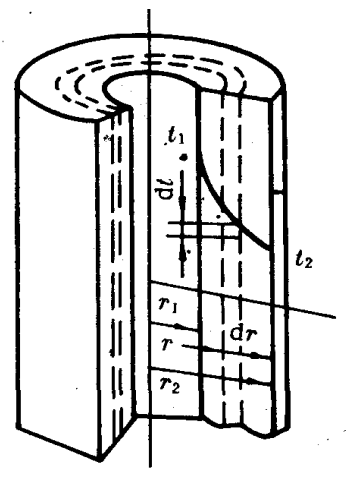

Figure 5 Heat conduction through a cylinder wall

The heat conduction differential equation and the corresponding boundary conditions are

$$
\begin{array}{ll}
r=r_{1}, & t=t_{1} \\
r=r_{2}, & t=t_{2}
\end{array}
$$


After continuous integral twice, the general solution is

$$
\begin{aligned}
& c_{1}=\frac{t_{2}-t_{1}}{\ln \left(r_{2} / r_{1}\right)} \\
& c_{2}=t_{1}-\ln r_{1} \frac{t_{2}-t_{1}}{\ln \left(r_{2} / r_{1}\right)}
\end{aligned}
$$

In the formula above, $c_{1} 、 c_{2}$ are decided by boundary conditions, The boundary conditions are used aiming at coupled solution. The temperature distribution for substitution

$$
t=t_{1}+\frac{t_{2}-t_{1}}{\ln \left(r_{2} / r_{1}\right)} \ln \left(r / r_{1}\right)
$$

Thus it can be seen,the temperature distribution in the cylinder wall is logarithmic curve.the derivative can be obtained

$$
\frac{d t}{d r}=\frac{1}{r} \frac{t_{2}-t_{1}}{\ln \left(r_{2} / r_{1}\right)}
$$

Getting into the Fourier law please

$$
q=-\lambda \frac{d t}{d r}=\frac{\lambda}{r} \frac{t_{1}-t_{2}}{\ln \left(r_{2} / r_{1}\right)}
$$

Thus in steady state heat conduction through the cylinder wall,the heat flux at different radius is inversely proportional to the radius.but the heat flux $\Phi$ through the whole cylinder wall is constant, and does not vary with radius. The type of the two sides of each type is multiplied by $2 \pi r l$.

$$
\Phi=2 \pi r l q=\frac{2 \pi \lambda l\left(t_{1}-t_{2}\right)}{\ln \left(r_{2} / r_{1}\right)}
$$

According to the definition of thermal resistance, the thermal conductivity of the whole cylinder wall is the thermal resistance.

$$
R=\frac{\Delta t}{\Phi}=\frac{\ln \left(d_{2} / d_{1}\right)}{2 \pi \lambda l}
$$

When the analysis of multi - layer cylinder wall, the principle of series thermal resistance is used,the thermal conductivity of a multi layer cylinder wall, as shown in Figure 6.

$$
\Phi=\frac{2 \pi l\left(t_{1}-t_{4}\right)}{\ln \left(d_{2} / d_{1}\right) / \lambda_{1}+\ln \left(d_{3} / d_{2}\right) / \lambda_{2}+\ln \left(d_{4} / d_{3}\right) / \lambda_{3}}
$$

Figure 6 Multilayer cylinder wall

Because the study of current heat on heat transfer model of multi-layer cone wall are not mature e nough. When we compute the heat loss of cyclone vertebral part, it is divided into two parts.

Through simulation the result shows that the temperature distribution of Cyclone separation device vertebral part of outside wall is uniform, and heat conduction direction is along generatrix of outside normal line direction. So using respectively in each part taking equivalent of multi-layer 
cylinder wall calculates its thermal loss. We regard approximately it as corresponding part of cone tube wall thermal loss.Finally,two parts of thermal loss are added to get thermal loss of whole cyclone separation device vertebral body part.

\subsection{The physical model and caclulation model about the rear smoke channel}

It is got from the specification of boiler design that the rear smoke channel is decorated with coated superheater in this $220 \mathrm{t} / \mathrm{h}$ circulating fluidized bed, the high temperature superheater and low temperature superheater are decorated in turn by the flue gas flow, the economizer is arranged at the rear smoke channel in the bottom of the superheater, the high temperature superheater and low temperature superheater are suspended by hanging pipe which is in the economizer.The first level water spray attemperator is set between the platen platen superheater and low temperature superheater, the second level water spray attemperator is set between the platen platen superheater and high temperature superheater. There are a lot of difficulties in calculation and simulation because of the complex structure in coated superheater, so the heat loss of the rear smoke channel in superheater is calculated by using the outside wall temperature of the rear smoke channel which is got by the simulation of economizer to replace the same temperature of superheater in the simulation of economizer.

The consequence is calculated by using the average temperature of the flue gas in the simulation of economizer and air preheater, so the temperature of outer wall should be distributed evenly in rear smoke channel of economizer and air preheater in the result of the simulation. Therefore the rear smoke channel was simulated in 2D when it is build to the structure. The model was showed in figure7.

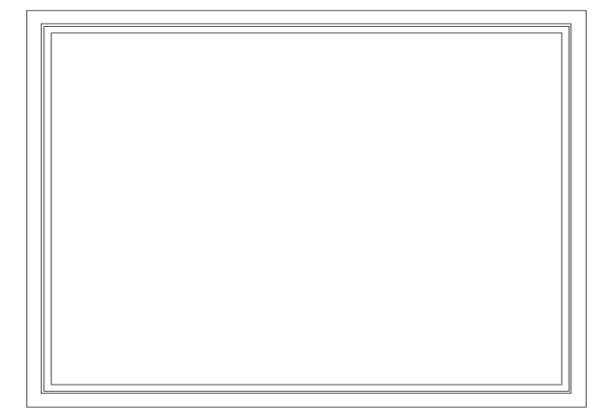

Figure7 The part model of rear smoke channel

The calculation model of rear smoke channel is similar to the calculation model of furnace.

\section{Conclusions}

1) The simulation temperature distribution of each part of the circulating fluidized bed boiler is showed in Figure8, Figure9, Figure10, Figure11.

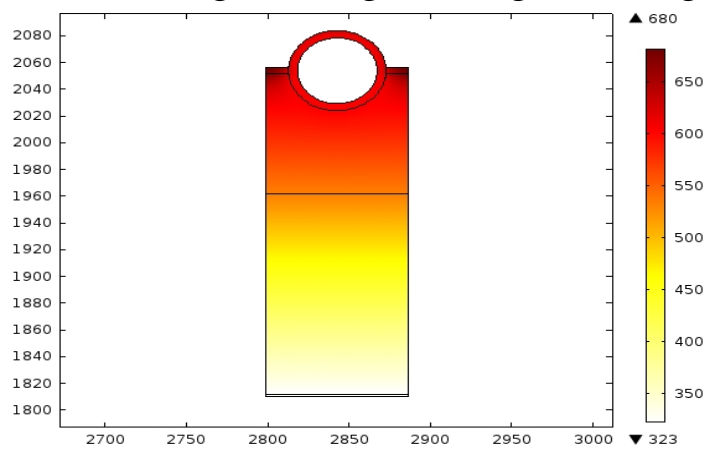

Figure8 Furnace temperature distribution

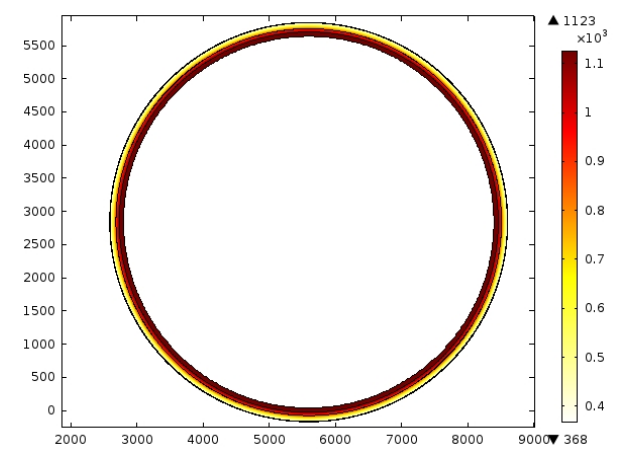

Figure 9 Partial temperature distribution of the vertebral body in the cyclone separator 


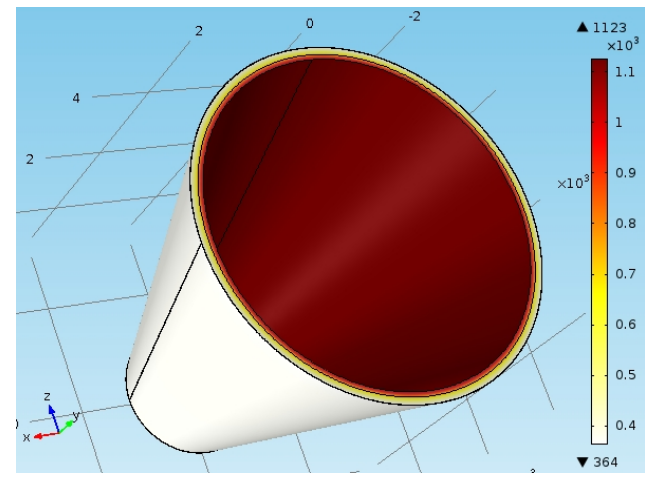

Figure10 Partial temperature distribution of the vertebral body in the cyclone separator

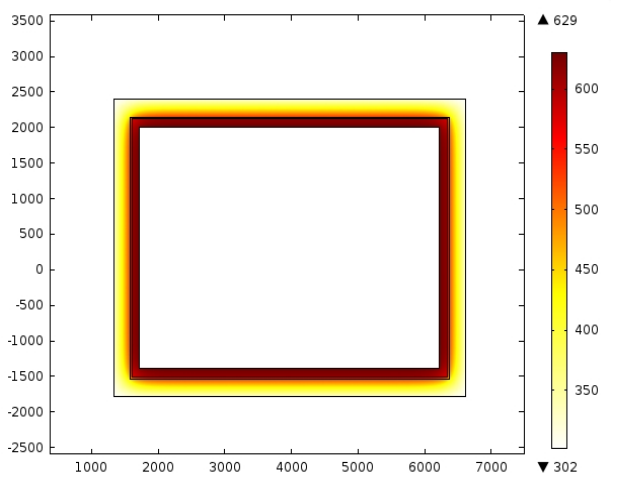

Figure 11 Temperature distribution diagram of the rear smoke channel

2) Simulation of the temperature of the circulating fluidized bed boiler:Partial surface temperature of the furnace is $48.5^{\circ} \mathrm{C}$ 、 Partial surface temperature of cyclone separator is $94.46^{\circ} \mathrm{C}$, partial surface temperature of vertebral body is $97.88^{\circ} \mathrm{C}$ 、 tail flue surface temperature is $48.90^{\circ} \mathrm{C}$.

3) Parts of the circulating fluidized bed boiler heat loss is furnace partial heat loss $(128.706 \mathrm{KW})$ 、 partial heat loss of cyclone separator(76.359KW) and partial cooling loss of tail flue $(57.069 \mathrm{KW})$.

\section{Acknowledgements}

This work was financially supported by the project supported by the Quality Supervision, Inspection and Quarantine of Science and Technology Plan Projects (2013QK022) and the National Key Technology R\&D Program of China (2014BAA02B02).

\section{References}

[1] Xuanming Cui.The Report of China Energy Development ,2009.

[2] Xuguo Zhao. Working Principle and Structural Design of 220t/h Cyclic Fluid Bed Boilers[J].

Mechanical Engineering and Automation,2007(2):114-116.

[3] Zhikun Liu. The Analysis about Measurement of Heat loss and Calculation in 300MW Cyclic

Fluid Bed Boilers [J].RailWay Construction Technology ,2011,1.

[4] Fudi Yao.The Research about Design of The furnace wall structure in Power station boilers . Boiler Technology,2005.35(6):9-13.

[5] Leming Cheng,Qinghui Wang,Zhenglun Shi,etc. Heat Transfer in Large Scale Cyclic Fluid Bed Boilers[J]. Power Engineering,2006.26(3):305-310.

[6] 《The method about Design and Calculation of Industrial Boilers》56.

[7] Qifang Zhao. The Introduction of Furnace wall construction processes in Cyclic Fluid Bed Boilers. China Academic Journal Electronic Publishing House.2006. 